\title{
Long term effects of withholding phosphate application on North Island hill country: Ballantrae
}

M.G. Lambert, D.A. Clark and A.D. Mackay

Grasslands Division, DSIR,

Private Bag, Pahnerston North

\begin{abstract}
In a farmlet grazing trial at DSIR's Ballantrae Hill Country Research Station near Woodville the effect of withholding phosphate application was investigated. Soils are yellow-brown earths and related steepland soils with low phosphate retention, and average annual rainfall is $1200 \mathrm{~mm}$. Four 10 ha farmlets, 2 each with histories of high (HF) or low (LF) superphosphate application, had annual applications continued at 125 (LF-LF) or 375 (HF$\mathrm{HF}) \mathrm{kg} / \mathrm{ha}$; or discontinued on one farmlet in each case (LF-NF and HF-NF), starting in 1981. Soil Olsen P level decreased on the HF-NF area, but not on LF-NF and pasture production decreased by 4.6 and $\mathbf{1 . 7 \%}$ p.a. respectively. Botanical composition was affected only on the HF-NF farmlet. Ewes were lighter as a result of not applying fertiliser. Ewe and lamb wool production, and lamb liveweight, were reduced by an average 1.2 , 3.7 and $2.6 \%$ p.a., respectively, over the 7 years. A phosphate application trial suggested that reactive phosphate rock was as effective as superphosphate in stimulating legume responses in the 1st year after restarting phosphate application, and had greater residual activity.
\end{abstract}

Keywords fertiliser, withholding, cessation, phosphate, superphosphate, hill country, pastures, soil fertility, wool, sheep

\section{INTRODUCTION}

In times of economic adversity farmers reduce discretionary expenditure. Fertiliser application is one of the easiest costs to reduce, and this option has been widely used on sheep and beef farms in the past 4 years. During the period $1975 / 76$ to $1979 / 80$ annual application of fertiliser was about $21 \mathrm{~kg} /$ stock unit (SU), during $1980 / 81$ to $1984 / 8515 \mathrm{~kg} /$ su, and during $1985 / 86$ to $1987 / 88$ only $9 \mathrm{~kg} / \mathrm{su}$ (NZMWBES 1988).
A grazing trial was run from 1981 until 1988 in steep hill country near Woodville, in order to quantify effects of withholding superphosphate application on previously fertilised land. Soil fertility and pasture and animal performance were measured.

\section{METHODS}

\section{Site and fertiliser application details}

Four 10-ha farmlets at the Ballantrae Hill Country Research Station of Grasslands Division, DSIR, which had been part of a previous grazing trial (Lambert et al.1983), were used. Data collected in the 3 years before the present trial started are presented here in some instances, and used as a basis for adjustment of data sets in others, in order to tae into account pretrial differences in the present trial in which fertiliser treatments were not replicated. Two of the farmlets were high fertiliser (HF) and 2 low fertiliser (LF) treatments (Table 1), and little or no fertiliser had been applied before 1973. From 1981 on, one of the LF (LF-LF) and one of the HF (HF-HF) farmlets continued to receive 'maintenance' superphosphate dressings, while the other in each instance (LF-NF, HF-NF) did not. The experimental area is at $250-350 \mathrm{~m}$ altitude, and average annual rainfall is about 1200 $\mathrm{mm}$. Soils are yellow-brown earths and related steepland soils; Ngamoko silt loam from silty drift material, and Mangamahu steepland soil from silty sandstone (R.H. Wilde pers. comm.). Phosphate retention is 21 to $34 \%$, and $\mathrm{pH} 5.1$ for $\mathrm{LF}$ and 5.4 for HF treatments.

In May 1985 fertiliser response trials were started, and continued for 2 years, on the LF-LF and LF-NF farmlets. Treatments were control, superphosphate (SP) and 'as received' North Carolina reactive phosphate rock (RPR). Each material was applied at 20, 40 and $60 \mathrm{~kg} \mathrm{P} / \mathrm{ha}$, calculated as citric acid-soluble $\mathrm{P}$ for $\mathrm{SP}$ and total $\mathrm{P}$ for RPR, and a basal dressing of sulphur was applied (Mackay \& Wewala 1989). Results presented here are means across application rates.

Table 1 Fertiliser treatments. Superphosphate application rates $(\mathrm{kg} / \mathrm{ha})$ during 1973 to 1987

\begin{tabular}{|c|c|c|c|c|c|c|c|c|c|c|c|c|c|c|c|}
\hline Treatment & 1973 & 1974 & 1975 & 1976 & 1977 & 1978 & 1979 & 1980 & 1981 & 1982 & 1983 & 1984 & 1985 & 1986 & 1987 \\
\hline$\overline{L F-L F}$ & 250 & 250 & 250 & 0 & 125 & 125 & 125 & 125 & 125 & 125 & 125 & 125 & 125 & 125 & 125 \\
\hline LF & 250 & 250 & 250 & 0 & 125 & 125 & 125 & 125 & 0 & 0 & 0 & 0 & 0 & 0 & 0 \\
\hline HF-HF & 250 & 250 & +750 & 500 & 875 & $500+$ & +500 & 375 & 375 & 375 & 375 & 375 & 375 & 375 & 375 \\
\hline HF-NF & 250 & 250 & +750 & 500 & 875 & $500 \mathrm{t}$ & +500 & 375 & 0 & 0 & 0 & 0 & 0 & 0 & 0 \\
\hline
\end{tabular}

$+1250 \mathrm{~kg} / \mathrm{ha}$ agricultural lime applied

$\dagger+2500 \mathrm{~kg} / \mathrm{ha}$ agricultural lime applied 


\section{Stock management}

The 4 farmlets were set-stocked with Romney breeding ewes, and lambs were weaned off the area in December in most years, but in January in 1982 and 1986. Replacement 2-tooths were drawn randomly from a pool after ewe culling each autumn. Stocking rate was 16.1 ewes/ha on HF farmlets, and 12.0 on LF farmlets during the first 2 years then subsequently 10.3 ewes/ha.

\section{Measurements}

Pasture and soil measurements were made at 18 permanent sites per farmlet, located in 9 slope-aspect strata (Lambert et al. 1983). Slope strata were 1-120 (low), 13-250 (medium) and $>26^{\circ}$ (high). Pasture production was measured using $0.5 \mathrm{~m}^{2}$ grazing exclosures and a 'trim' technique. Botanical composition was determined by hand-dissection of subsamples of harvested material from exclosures, and species categories were high-fertility-responsive (HFR) grasses (e.g. ryegrass, cocksfoot, Yorkshire fog), lowfertility-tolerant (LFT) grasses (e.g. browntop, sweet vernal, crested dogstail), legumes (white, red and suckling clovers and Lotus pedunculatus) and other species (mainly flatweeds).

Soil samples (0-75 $\mathrm{mm}$ depth) were taken from the permanent measurement sites each winter and bulked across aspects for analysis.

Sheep were weighed each month, lambing \% recorded, and lamb liveweight (LW) recorded at weaning. Ewe wool weight was recorded at shearing (March and November for 1982 to 1984, November only thereafter) and lamb wool weight was estimated by shearing a sample of lambs at weaning. In 1987, 20 ewe fleeces from each farmlet were analysed for clean wool base and vegetable matter content, fibre diameter, colour, staple strength, and degree of cotting.

\section{RESULTS}

\section{Soil Olsen P}

Olsen P level (averaged across slope classes) was low (4-7) and similar for LF-LF and LF-NF throughout the 7 years (Figure 1). Olsen $P$ increased on the HF-HF and decreased on the HF$\mathrm{NF}$ area. Similar trends to these occurred on low, medium and high slope categories on the LF-LF and LF-NF farmlets (average Olsen P 7, 6 and 4 respectively); and on the $\mathrm{HF}-\mathrm{HF}$ (Olsen $\mathrm{P}$ increase from 11 to 22,12 to 17 and 7 to 14 respectively) and HF-NF (Olsen P decrease from 11 to 9, 12 to 8 and 11 to 5 respectively) treatments.

\section{Pasture production}

Average annual pasture production was $8.4 \mathrm{tDM} /$ ha for the LF-LF farmlet, and 12.9 t DM/ha for the HF-HF farmlet. Production on the LF-NF (compared with the LF-LF) treatment decreased on average $1.7 \%$ each year over the 7 years (Fig. 2). Production on the HF-NF (compared with the HFI-IF) farmlet decreased on average $4.6 \%$ per year. This represented average annual decreases of 0.14 and $0.60 \mathrm{tDM} /$ ha respectively.

The predicted 7-year cumulative reduction in pasture production as a result of withholding phosphate was 12 and $32 \%$ for the LF-NF and HFNF treatments respectively (Figure 2). Predicted reductions on low, medium and high slope classes within the LF-NF treatment were 22, 10 and $3 \%$

Table 2 Ewe liveweight (kg) in March/April and October/November. Year 0 values are averages for 1979-81.

\begin{tabular}{|c|c|c|c|c|c|c|c|c|}
\hline \multirow[b]{2}{*}{ Year } & \multicolumn{4}{|c|}{ March / April } & \multicolumn{4}{|c|}{ October / November } \\
\hline & LF-LF & LF-NF & HF-HF & HF-HF & LF-LF & LF-NF & HF-HF & HF-NF \\
\hline $\begin{array}{l}\mathbf{0} \\
1\end{array}$ & 53.2 & 53.1 & 54.9 & 55.1 & 46. 1 & 44. 1 & 45. 1 & 45.2 \\
\hline $\begin{array}{l}2 \\
3\end{array}$ & $\begin{array}{l}50,047,5 \\
51.7\end{array}$ & $\begin{array}{l}52.348 .2 \\
49.9\end{array}$ & $\begin{array}{l}49.951 .1 \\
53.1\end{array}$ & $\begin{array}{l}49.052 .2 \\
50.6\end{array}$ & $\begin{array}{l}43.841 .4 \\
44.1\end{array}$ & $\begin{array}{l}42.038 .7 \\
43.0\end{array}$ & $\begin{array}{r}43.2 \quad 42.8 \\
40.8\end{array}$ & $\begin{array}{l}13.640 .1 \\
39.4\end{array}$ \\
\hline $\begin{array}{l}4 \\
5\end{array}$ & 51.1 & 52.1 & 50.8 & 50.9 & 43.8 & 39.8 & 41. 4 & 39.6 \\
\hline $\begin{array}{l}6 \\
7\end{array}$ & $\begin{array}{l}52.947 .4 \\
53.0\end{array}$ & $\begin{array}{l}52.246 .1 \\
52.7\end{array}$ & $\begin{array}{l}48.454 .0 \\
55.3\end{array}$ & $\begin{array}{l}43.952 .4 \\
52.4\end{array}$ & $\begin{array}{l}48.646 .1 \\
45.7\end{array}$ & $\begin{array}{l}45.24^{45.8} \\
41.7^{2}\end{array}$ & $\begin{array}{r}48.3 \quad 49.5 \\
46.6\end{array}$ & $\begin{array}{l}42.542 .1 \\
42.4\end{array}$ \\
\hline
\end{tabular}

Table 3 Greasy wool weight $(\mathrm{kg} / \mathrm{ha})$ and weaned lamb liveweight $(\mathrm{kg} / \mathrm{ha})$ production, corrected for differences at trial start. Predicted annual and cumulative ('l-year total) declines caused by withholding phosphate.

\begin{tabular}{|c|c|c|c|c|c|c|c|c|c|c|c|c|}
\hline & \multicolumn{4}{|c|}{ Ewe wool } & \multicolumn{4}{|c|}{ Lamb wood } & \multicolumn{4}{|c|}{ Lamb liveweight } \\
\hline & LF-LF & LF-NF & HF-HF & $\mathrm{HF}_{74} \mathrm{NF}$ & LF-LF & LF-NF & HF-HF & HF-NF & LF-LF & LF-NF & HF-HF & HF-NF \\
\hline Year & $\begin{array}{l}49 \\
44\end{array}$ & $\begin{array}{l}51 \\
46\end{array}$ & $\begin{array}{l}75 \\
68\end{array}$ & 68 & $\begin{array}{l}9.7 \\
5.3\end{array}$ & $\begin{array}{r}12.1 \\
8.1\end{array}$ & $\begin{array}{l}18.3 \\
11.0\end{array}$ & $\begin{array}{r}16.9 \\
9.1\end{array}$ & $\begin{array}{l}251 \\
153\end{array}$ & $\begin{array}{l}301 \\
161\end{array}$ & $\begin{array}{l}437 \\
301\end{array}$ & $\begin{array}{l}409 \\
278\end{array}$ \\
\hline 4 & 4756 & 46 & 67 & $\begin{array}{l}67 \\
68\end{array}$ & 1.19 .2 & 6.1 & $15,09.7$ & 13.19.1. & 24237 & 222210 & 307389 & 346311 \\
\hline 5 & 36 & 34 & 58 & 54 & 13.0 & 10.8 & 21.6 & 18.5 & 277 & 255 & 467 & 434 \\
\hline $\begin{array}{r}6 \\
7 \\
\text { Annua } \\
\text { Cumu }\end{array}$ & $\begin{array}{r}37 \\
40 \\
\%)\end{array}$ & $\begin{array}{c}34 \\
36 \\
1.5 \\
10.4\end{array}$ & $\begin{array}{l}63 \\
64\end{array}$ & $\begin{array}{l}58 \\
61 \\
0.9 \\
6.1\end{array}$ & $\begin{array}{l}8.2 \\
6.4\end{array}$ & $\begin{array}{c}6.56 \\
5.8 \\
4.1 \\
28.8\end{array}$ & $\begin{array}{l}14.6 \\
10.1\end{array}$ & $\begin{array}{c}11.0 \\
6.9 \\
3.3 \\
22.9\end{array}$ & $\begin{array}{c}229 \\
182\end{array}$ & $\begin{array}{r}196 \\
175 \\
2.7 \\
18.7\end{array}$ & $\begin{array}{l}406 \\
286\end{array}$ & $\begin{array}{r}328 \\
208 \\
2.5 \\
17.7\end{array}$ \\
\hline \multicolumn{2}{|c|}{ Probability of decrease (\%) } & 81 & & 92 & & 94 & & 93 & & 93 & & 86 \\
\hline
\end{tabular}


Table 4 Ewe wool characteristics in 1987

\begin{tabular}{lcccc}
\hline & LF-LF LF-NF & HF-HF & HF-NF \\
\hline Clean wool base (\%) & 68.7 & $68.8 \mathrm{~ns}$ & 67.3 & $68.7 \mathrm{~ns}$ \\
Vegetable matter (\%) & 0.15 & $\mathbf{0 . 2 0 *}$ & 0.09 & $0.15^{*}$ \\
Fibre diameter (pm) & $\mathbf{4 . 0}$ & $35.1 \mathrm{~ns}$ & 36.4 & $\mathbf{3 5 . 1}$ \\
'Degree of cotting & $\mathbf{6 2 . 2}$ & $4.6 \mathrm{~ns}$ & 4.5 & $4.5 \mathrm{~ns}$ \\
2Wool brightness & $\mathbf{- .}$ & $61.3 \mathrm{~ns}$ & 60.9 & $\mathbf{6 2 . 0 *}$ \\
3Wool yellowness & $\mathbf{3 . 7}$ & $\mathbf{4 . 0} \mathrm{ns}$ & 4.1 & $2.9^{*}$ \\
'Staple strength & 5.2 & $\mathbf{4 . 9} \mathrm{ns}$ & 5.3 & $4.6 \mathrm{~ns}$
\end{tabular}

$\mathrm{J}_{2}=$ hard cot, $8=$ not holding together

2 Y parameter.

3 Y-Z parameter.

$42=$ very weak, $8=$ strong

respectively, and for the HF-NF treatment 24,25 and $55 \%$ respectively.

Seasonality of pasture production was not significantly affected by withholding phosphate. For years 4 to 7 , average annual pasture production from no-fertiliser farmlets was $83.4 \%$ of that where fertiliser was continued. The equivalent seasona values (with standard errors in parentheses) were $80.3( \pm 11.0), 89.9( \pm 19.8), 83.9( \pm 22.2)$ and 85.8 $( \pm 11.0)$ for summer, autumn, winter and spring respectively.

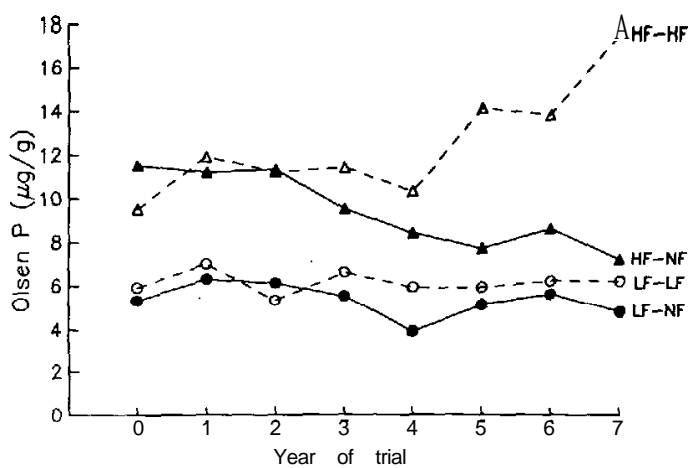

Figure 1 Soil Olsen $\mathrm{P}$ values. Year 0 values are averages for 1979-S 1 .

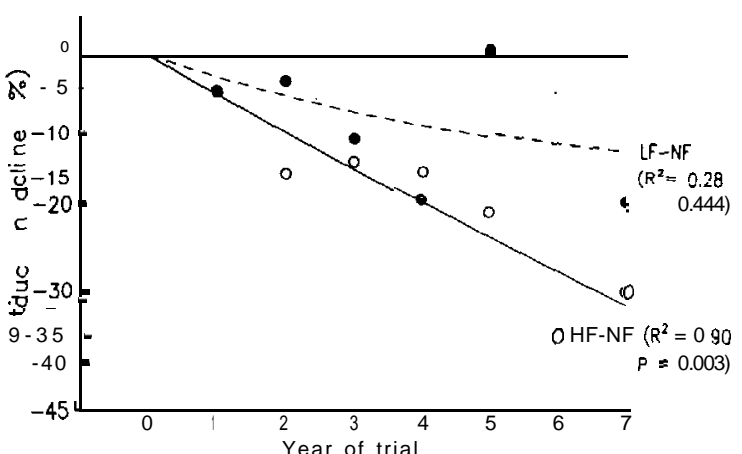

Figure 2 Actual and predicted (quadratic polynomials) declines in pasture production (\%) on LF-NF and HF-NF farmlets. Zero line is production on LF-LF or HF-HF farmlet in any particular year. Data corrected for pretrial (1979-81) differences.

\section{Pasture composition}

There were no consistent changes in botanical composition (meaned over slopes) of LF-NF compared with LF-LF pastures. Average content of HFR grasses was $21 \%$, of LFT grasses $66 \%$, of legumes $\mathbf{7 \%}$, and of other species $6 \%$. Comparative composition for HF-HF pasture was $46 \%, 43 \%$, $9 \%$ and $2 \%$ respectively. HF-NF pastures tended to have lower HFR grass content $(41 \%)$ and higher LFT grass (46\%) and other species (5\%) content by year 7 .

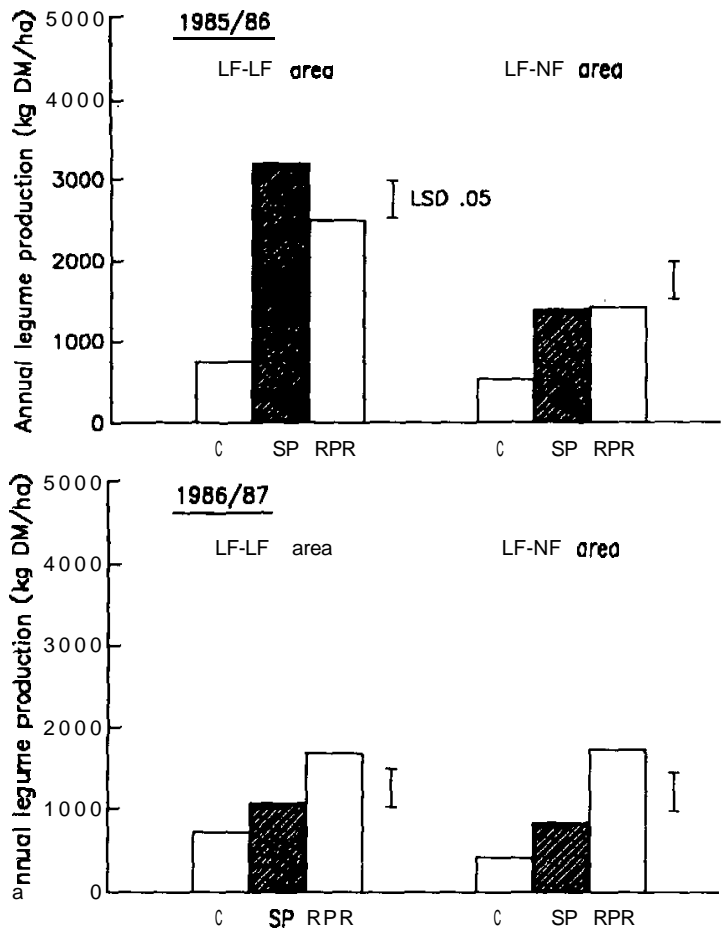

Figure 3 Responses in legume component (kg DM/ha) to application of superphosphate (SP) or reactive phosphate rock (RPR), compared with control (C).

\section{Ewe liveweight}

Liveweight (LW) in March/April was similar for LF-LF and LF-NF ewes throughout the trial, but October/November LW was lower in years 5-7 (Table 2). Liveweight of HF-NF ewes was less than that of HF-HF ewes in both March/April and October/November in the second half of the trial.

\section{Wool and lamb production}

Predicted reductions in ewe wool production as a result of withholding fertiliser were small (0.9-1 .5\% p.a.), and reductions in lamb wool (3.3-4.1\% p.a.) and lamb weaned LW (2.5-2.7\% p.a.) production were a little greater (Table 3). Reductions were similar in magnitude for LF-NF and HF-NF treatments. Average lamb docking percentage was 100 where fertiliser application was continued, and 95 where it was discontinued. 
Vegetable matter content of wool was greater in both treatments where fertiliser was withheld (Table 4), but fibre diameter and wool yellowness decreased, and brightness increased in wool from HF-NF ewes.

\section{Fertiliser trial}

Application of phosphate fertiliser in year 5 resulted in larger responses in legume production on the LFLF than on the LF-NF area in the first year after application (Figure 3). On the LF-LF area response to SP was greater than to RPR in the 1st year, but smaller in the 2nd year after application. On the LF$\mathrm{NF}$ area responses to SP and RPR were similar in the 1 st year, but greater for RPR in the 2 nd year.

\section{DISCUSSION}

Withholding superphosphate application for 7 years did not affect soil Olsen $\mathrm{P}$ level, or pasture botanical composition on the farmlet previously receiving 125 $\mathrm{kg} / \mathrm{ha}$ superphosphate annually, but did reduce pasture (cumulative 12\%) and animal (cumulative 10-29\%) production. Withholding phosphate resulted in lower Olsen $\mathrm{P}$ values, and a greater decrease in pasture production (cumulative 32\%) on the area previously receiving higher super-phosphate dressings. Pasture compositional changes were small, away from species such as ryegrass towards more browntop, sweet vernal, and flatweeds. Despite the greater impact on soil fertility and pastures, animal production was reduced in only the same proportion as for the LF-NF treatment.

Seasonality of pasture production was not changed where fertiliser was withheld, just as seasonality was not changed in the first 6 years of application in the earlier phases of the fertiliser work at Ballantrae (Lambert et al. 1983). However, effects of applying fertiliser and increasing stocking rate on botanical composition were much more marked in that work (Lambert et al. 1986) than in the present work where stocking rate was constant within historical fertiliser treatments. Reducing stocking rates when withholding phosphate, in anticipation of decreased pasture production, may increase rates of pasture reversion.

Effects of withholding fertiliser on animal production were buffered strongly by the ewes, especially as stocking rates and pasture utilisation were already higher at the start of the trial than those normally used on similar commercial farms. However, during the entire trial period for the LFNF treatment, and during years 1 to 5 for the HF$\mathrm{NF}$ treatment, reductions in pasture production were less than those normally experienced $(\mathrm{t}-23 \%)$ as a result of normal year-to-year climatic variation (Lambert et al. 1983).

Such variation is commonly coped with by normal farm management practices. In this trial, the continued reduction in pasture production resulted in ewes producing less wool of only slightly different qualityReproductive performance was also affected, especially in the HF-NF treatment where docking percentages averaged 88 in years 5 to 7 , compared with 109 for HFHF ewes. This reflected the severe. weight loss sustained by these ewes each winter, and liveweight. Lambs were lighter at weaning in the NF treatments, and this coupled with shortage of feed after weaning would pose increased difficulties in rearing suitable ewe replacements. This problem was not encountered in the present trial because of the policy adopted of not rearing replacements on the farmlets.

Other measurements within the present trial suggest that on all 4 . treatments available phosphate was still the major nutrient limitation to legume growth, even though sulphur applied in superphosphate had been much less strongly retained in the soil (Mackay et al. 1988; Lambert et al. 1988). Results from the subsidiary fertiliser trial run within the main trial suggest that where phosphate application has been continued, RPR fertilisers will be slower to act but as effective as superphosphate over 2 years. Where fertiliser has not been applied for several years, and Olsen P levels are low, initial responses to phosphate application will be smaller, and RPRs appear to be particularly suitable for use in this situation

Acknowledgements D.A. Costall, P.J. Budding, Pieter Nes, and members of the Herbage Laboratory, Grasslands Division, for technical assistance. Dr G.A. Wickham for advice and assistance with wool quality measurements.

\section{REFERENCES}

Lambert, M.G.; Clark, DA.; Costall, D.A.; Budding, P.J. 1988. Phosphorus and sulphur accumulation after long-term superphosphate application to grazed hill country. Proceedings of Towards the More Efficient Use of Soil and Fertiliser Sulphur. Massey University, February 1988. pp 95-100.

Lambert, M.G.; Clark, D.A.; Grant, D.A.; Costall, D.A 1986. Influence of fertiliser and grazing managemen on North Island moist hill country 2. Pasture botanical composition. NZ Journal of Agricultural Research 29:1-10.

Lambert, M.G.; Clark, D.A.; Grant, D.A.; Costall, D.A.; Fletcher. R.H. 1983. Influence of fertiliser and grazing management on North Island moist hill country. 1 Herbage accumulation. NZ Journal of Agricultural Research 26:95-108.

Mackay, A.D.; Lambert, M.G.; Clark, D.A.; Saggar, S. Hedley, M.J. 1988. Pasture responses to sulphur and phosphorus application in southern North Island Hill Country. Proceedings of Towards the more Efficient Use of Soil and Fertiliser Sulphur. Massey University, February 1988. pp 285-291.

Mackay, A.D.; Wewala, G.S. 1989. Evaluation of partially acidulated phosphate fertilisers and reactive phosphate rock for hill pastures. Fertiliser Research (in press).

NZMWBES 1988. Annual Review of the New Zealand Sheep and Beef Industry. NZ Meat \& Wool Board's Economic Service, Publication No. 1985. 